\title{
APPLICATION OF THE TEMPERATURE OSCILLATION METHOD IN HEAT TRANSFER MEASUREMENTS AT THE WALL OF AN AGITATED VESSEL
}

\author{
S. Solnař*, M. Dostál, K. Petera, T. Jirout \\ Czech Technical University in Prague, Faculty of Mechanical Engineering, Department of Process Engineering, \\ Technická 4, Prague, Czech Republic \\ * corresponding author: stanislav.solnar@fs.cvut.cz
}

\begin{abstract}
The Temperature Oscillation Infra-Red Thermography (TOIRT) was used to measure convective heat transfer coefficients at the inner vertical wall of an agitated and baffled vessel. Two impellers were used: an axial six-blade impeller with pitched blades and the Rushton turbine. The TOIRT method represents an indirect method based on measuring the phase shift between the oscillating heat flux applied to one side of the heat transfer surface and the wall temperature response monitored by a contactless infra-red camera at the same side. On the basis of this phase shift, the TOIRT method can indirectly evaluate the heat transfer coefficient on the other side of the heat transfer surface. Two forms of experimental results are presented in this paper. The first one describes graphical dependencies of the local Nusselt number on the dimensionless distance from the vessel bottom for various Reynolds numbers. The second form describes the mean Nusselt number along the wall as a function of the Reynolds number.
\end{abstract}

KEYWORDS: TOIRT, temperature oscillation method, agitated vessel, wall, heat transfer coefficient.

\section{INTRODUCTION}

One of the most common operations in chemical, food and pharmaceutic industries is a mixing of liquid materials. This operation frequently requires cooling or heating the agitated liquid. The required size of the transfer surface depends mainly on the intensity of the heat transfer between the agitated liquid and the heat transfer surface. The heat transfer rate $\dot{Q}$ depends on the size of heat transfer surface $S$, heat transfer coefficient $\alpha$, and mean temperature difference $\Delta T$.

$$
\dot{Q}=\alpha S \Delta T \text {. }
$$

Therefore, the knowledge of the heat transfer coefficient $\alpha$ at the heat transfer surface (for example, at the vessel bottom, vessel walls, baffles, inserts, etc.) is very important for an optimum design of the mixing equipment.

Experimental methods based on measuring various thermal quantities (heat fluxes, heat flow rates, temperatures) are the ones most frequently used for determining values of heat transfer coefficients. Besides that, methods based on an analogy between various transport phenomena (heat and mass transport, for example) can also be used. Nowadays, numerical methods implemented in many CFD packages solving momentum and heat transport equations are also frequently used to determine heat transfer coefficients in laminar as well as turbulent flow regimes. In principle, the methods based on measuring thermal quantities use (1). With the liquid and wall temperatures along with the heat flow rate transferred between the wall and liquid determined, the heat transfer coefficient can be expressed from this equation (assuming we know the size of the heat transfer surface). The heat flow rate can be measured by various techniques. One possibility is using thin film heat flux sensors, which measure small temperature differences arising from the heat flow rate through a thin film element made of material with known properties. Transient methods determine the heat flow rate, for example, on the basis of a monitored temperature profile of the liquid accumulating the supplied heat, see [1, 2, for a description of this approach.

In general, any experimental method where we can derive some relationship between the heat transfer coefficient and directly measured physical quantities can be used to determine heat transfer coefficients. Wandelt and Roetzel [8] found an analytical solution of the case where a plate (representing the heat transfer surface) is heated from one side by an oscillating (sine) heat flux. This solution depends on properties of the plate and heat transfer coefficients on both sides. By measuring the time dependency of the plate surface temperature and on the basis of their mathematical model, it is then possible to indirectly evaluate the heat transfer coefficient on the other side of the plate.

Wandelt and Roetzel's temperature oscillation infrared thermography method (TOIRT) has been extensively studied by Freund [9] in his dissertation thesis. Freund studied the theoretical background of this method and focused on some well-known cases like a pipe flow or a jet impinging a plate perpendicularly. Freund and Kabelac [10] presented another study based on the TOIRT method where heat transfer coefficients in a plate heat exchanger were measured. 


\begin{tabular}{lcccclc}
\hline & $C$ & $m$ & $n$ & $L_{\text {char }}$ & \multicolumn{1}{c}{ Note } & Ref. \\
\hline $\mathrm{Nu}_{0}$ & 0.726 & 0.53 & - & $d$ & $h / d=1, \operatorname{Pr}=0.71$ & {$[3]$} \\
\hline$\overline{\mathrm{Nu}}$ & 0.424 & 0.57 & - & $d$ & $h / d=1, \mathrm{Pr}=0.71,0 \leq r / d \leq 1$ & {$[\underline{3}$} \\
\hline$\overline{\mathrm{Nu}}$ & 0.150 & 0.67 & - & $d$ & $h / d=1, \operatorname{Pr}=0.71,0 \leq r / d \leq 2$ & {$[3]$} \\
\hline $\mathrm{Nu}_{0}$ & 1.2 & 0.5 & $1 / 3$ & $d$ & $h / d=1$ & {$[\underline{4}]$} \\
\hline$\overline{\mathrm{Nu}}_{6 \mathrm{BD}}$ & 0.81 & 0.68 & 0.33 & $D$ & $10^{5}<\mathrm{Re}<7 \cdot 10^{5}$ & {$[\underline{5}$} \\
\hline$\overline{\mathrm{Nu}}_{6 \mathrm{BD}}$ & 1.15 & 0.65 & 0.33 & $D$ & $30<\operatorname{Re}<4 \cdot 10^{4}$ & {$[6]$} \\
\hline$\overline{\mathrm{Nu}}_{6 \mathrm{BD}}$ & 0.76 & $2 / 3$ & $1 / 3$ & $D$ & $4000<\operatorname{Re}<28 \cdot 10^{4}$ & {$[\underline{6}]$} \\
\hline$\overline{\mathrm{Nu}}_{6 \text { BD }}$ & 0.73 & 0.67 & 0.33 & $D$ & $10^{4}<\operatorname{Re}<5 \cdot 10^{4}$ & {$[7]$} \\
\hline$\overline{\mathrm{Nu}}_{6 \text { PBT45 }}$ & 0.43 & 0.67 & 0.33 & $D$ & $10^{4}<\operatorname{Re}<5 \cdot 10^{4}$ & {$[7]$} \\
\hline
\end{tabular}

TABle 1. Parameters $m, n$, and $C$ in correlation (4) for various cases in the literature. $L_{\text {char }}$ represents the characteristic length in equation (2). Subscript 0 refers to the stagnant point in the impinging jet. 6BD refers to six-blade disc impeller (Rushton turbine), and 6PBT45 to six-pitched-blade turbine impeller (pitched angle $45^{\circ}$ ) in common geometry configuration, i.e. $H / D=1, d / D=1 / 3$.

Freund et al. [11] also used the TOIRT method in a study of heat transfer in spray cooling systems.

Impinging jets are widely used in industrial applications for local cooling and heating. Many papers dealing with heat transfer in various geometries can be found in the literature and impinging jets represent frequent reference cases for testing the results of heat transfer measurements or numerical simulations. In studies of impinging jets, most of the authors focus on cases with the nozzle-plate spacing related to the nozzle diameter greater then 1 , only few authors deal with relative distances $h / d$ less than 1 or around 1 . Lytle and Webb [3] measured local values of a heat transfer coefficient for $0.1<h / d<6$ and the Reynolds number within the range of $3600<\operatorname{Re}<27600$. They presented the radial dependency of the local Nusselt number, correlations for the Nusselt number in the stagnation point and the mean Nusselt numbers averaged over the heat transfer surface.

Katti and Prabhu 4 presented results of the radial dependency of the local Nusselt number based on experimental data for $0.5<h / d<8$ and $12000<\operatorname{Re}<$ 28000. They presented expressions describing the local Nusselt number in the stagnant, transition, and wall jet regions, and they also proposed a correlation for the stagnant Nusselt number. Persoons et al. 12 studied local heat transfer in a pulsating impinging jet for the nozzle-to-surface spacing $1 \leq h / d \leq 6$, Reynolds numbers $6000 \leq \operatorname{Re} \leq 14000$, and pulsation frequency $0 \leq f \leq 55 \mathrm{~Hz}$ ). Many works also focused on numerical modelling of impinging jets, for example, Draksler et al. [13] or Jensen and Walther [14]. Zuckerman and Lior [15] published an extensive review paper on impinging jets summarizing empirical correlations and numerical simulation techniques.

Another very frequent field of study is the heat transfer in agitated vessels. Many papers can be found about heat transfer in the whole vessel (Wichterle [16], Mohan et al. [17, Akse et al. [5], Karcz [7]) but only a few deal with local heat transfer coefficients at the bottom of the agitated vessel or at the vessel wall (Karcz and Cudak [18, Engeskaug et al. [19], Mohan et al. [17] and Akse et al. [5]).

Mohan et al. 17 presented a review of the heat transfer in agitated vessels. This work focused on heat transfer in single-phase and two-phase (gas-liquid) agitated systems equipped with either jacket or heat transfer coils. They also presented axial dependencies of local heat transfer coefficients in an air-water agitated system. The heat transfer in a jacketed vessel agitated by the standard Rushton turbine was described by Akse et al. [5]. Edwards and Wilkinson [6] also presented a review of the heat transfer in agitated vessels with various types of agitators and heat transfer surfaces. Typical correlation parameters (see equation 4) for the average Nusselt number in a vessel agitated by a six-blade disc impeller (Rushton turbine) are summarized in Table 1. Typical values of parameters for the average Nusselt number on the wall of the vessel agitated by the six-blade impeller with a pitch angle of $45^{\circ}$ published by Karcz [7] are also mentioned in this table.

The local convective heat transfer coefficients are usually evaluated by experiments or numerical models. Two most frequently used experimental methods are Thermochromic Liquid Method (TLC), see Vejrazka and Marty [20] for an example, and electro-diffusion method (EDD) (Karcz and Cudak [18). Usually, the measured values of heat transfer coefficients are expressed in terms of correlations for the dimensionless Nusselt number

$$
\mathrm{Nu}=\frac{\alpha d}{\lambda}
$$

where $d$ represents a characteristic length, it could be length of a plate, pipe diameter, impeller diameter, etc. In engineering practice, mean values of the Nusselt numbers averaged over the heat transfer surface are 
more frequently used

$$
\overline{\mathrm{Nu}}=\frac{1}{S} \int_{S} \mathrm{Nu} \mathrm{d} S .
$$

The dependency of local or mean Nusselt numbers is often expressed in the following form

$$
\mathrm{Nu}=C \operatorname{Re}^{m} \operatorname{Pr}^{n},
$$

where $C, m$ and $n$ are parameters, which are determined in the experiments. Table11 illustrates a comparison of typical values of these parameters in correlation (4) for some cases referenced above. The Reynolds number Re, in this correlation, is defined as

$$
\operatorname{Re}=\frac{u d \rho}{\mu}
$$

or, for mixing systems, with $N d$ substituted for the velocity $u$

$$
\operatorname{Re}_{\mathrm{M}}=\frac{N d^{2} \rho}{\mu}
$$

The Prandtl number is usually defined as

$$
\operatorname{Pr}=\frac{\nu}{a}=\frac{\mu c_{p}}{\lambda}
$$

Transport and thermophysical properties, in the correlations for the Nusselt number and corresponding dimensionless numbers (see equations above), are related to fluid (liquid).

\section{Theoretical BACKGROUND OF TOIRT}

The TOIRT method by Wandelt and Roetzel [8] is based on measuring the wall temperature with an IR camera (see Figure 1). This temperature depends on two main factors: heat transfer coefficients on both sides of the wall with thickness $\delta$ and modulated heat flux $q$. The heat flux is modulated by a sine function $q(t)=\hat{q} \sin (\omega t)$ and it is applied to one side of the wall. The temperature field monitored at the same side by the IR camera then shows a sinusoidal dependency. According to the TOIRT method, the phase shift between the sine-modulated heat flux and wall temperature response can be used to indirectly evaluate the heat transfer coefficient $\alpha_{0}$ on the other side of the wall.

The time and spatial dependency of the temperature $T$ in a homogeneous wall (with a thermal diffusivity $a_{\mathrm{w}}$ ) is described by Fourier's equation

$$
\frac{\partial T}{\partial t}=a_{\mathrm{w}}\left(\frac{\partial^{2} T}{\partial x^{2}}+\frac{\partial^{2} T}{\partial y^{2}}+\frac{\partial^{2} T}{\partial z^{2}}\right)
$$

by neglecting the lateral heat conduction in the wall (the first two partial derivatives on the right-hand side of the previous equation), it is possible to find an analytical solution in the case of the periodically

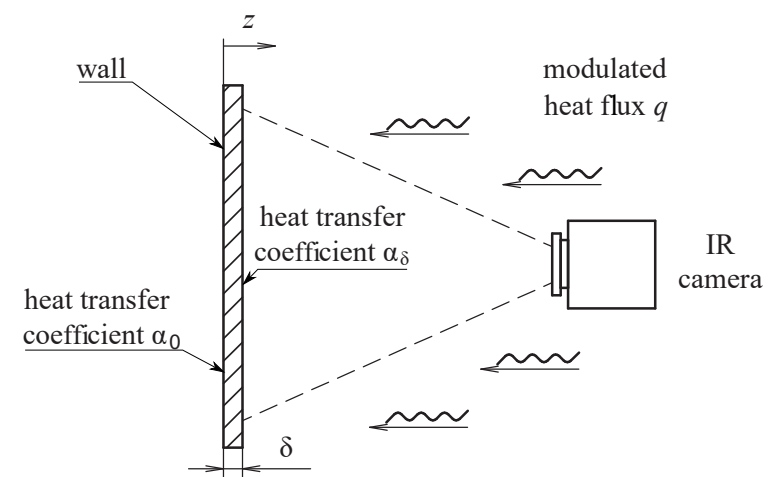

FiguRE 1. The temperature oscillation method for heat transfer measurement by Wandelt and Roetzel 8 .

oscillation heat flux. The boundary conditions of the third kind can be written as

$$
\begin{gathered}
\left.\lambda_{\mathrm{w}} \frac{\partial T}{\partial z}\right|_{\mathrm{z}=0}=\left.\alpha_{0} T\right|_{\mathrm{z}=0}, \\
\left.\lambda_{\mathrm{w}} \frac{\partial T}{\partial z}\right|_{\mathrm{z}=\delta}=\hat{q} \sin (\omega t)-\left.\alpha_{\delta} T\right|_{\mathrm{z}=\delta},
\end{gathered}
$$

where $\alpha_{0}$ is the heat transfer coefficient we are looking for, $\alpha_{\delta}$ is the heat transfer coefficient on the other side of the wall, $\omega$ is the angular frequency of the oscillating heat flux and $\hat{q}$ is its amplitude. The authors [8] used the Laplace transformation to solve this system of equations and found solution in the following form

$$
T(z, t)=A(z) \sin (\omega t-\varphi(z))
$$

where the phase shift $\varphi(z)$ at the surface with periodically oscillating heat flux can be described as

$$
\begin{aligned}
& \left.\tan \varphi\right|_{\mathrm{z}=\delta} \\
& =\frac{c_{1}+2 \xi \psi_{0} c_{2}+2 \xi^{2} \psi_{0}^{2} c_{3}}{2 \xi \psi_{0}(1+r) c_{0}+2 \xi^{2} \psi_{0}^{2}(1+2 r) c_{1}+4 \xi^{3} \psi_{0}^{3} r c_{2}+c_{3}} .
\end{aligned}
$$

Dimensionless parameters $r, \psi_{0}, \xi$ and $c_{0,1,2,3}$ in the previous equation are defined as

$$
\begin{aligned}
& r=\frac{\alpha_{\delta}}{\alpha_{0}} \quad \psi_{0}=\frac{\alpha_{0} a_{\mathrm{w}}}{\delta \lambda_{\mathrm{w}} \omega}, \quad \xi=\delta \sqrt{\frac{\omega}{2 a_{\mathrm{w}}}}, \\
& c_{0}=\cosh ^{2} \xi \cos ^{2} \xi+\sinh ^{2} \xi \sin ^{2} \xi \\
& c_{1}=\cosh \xi \sinh \xi+\cos \xi \sin \xi \\
& c_{2}=\cosh { }^{2} \xi \sin ^{2} \xi+\sinh ^{2} \xi \cos ^{2} \xi \\
& c_{3}=\cosh \xi \sinh \xi-\cos \xi \sin \xi .
\end{aligned}
$$

The big advantage of the equation (12) when determining the heat transfer coefficient $\alpha_{0}$ is no dependency on the amplitude of the heat flux. However, the amplitude size influences the accuracy of the measured surface temperature, which then has an indirect impact on the accuracy of the key quantity, that is the phase shift between the oscillating heat flux and 
the measured temperature response. Therefore, the correct and accurate evaluation of the heat transfer coefficient on the base of the experimental data depends mainly on the accuracy of this phase shift.

Figure 2 at the top illustrates a real temperature response measured by an IR camera at one point of the heat transfer surface. It is obvious that it does not oscillates around a constant average value as it would imply from boundary conditions $(9)$ and $(10)$ but it slowly increases with time. This increase is caused by the accumulation of heat in the measured volume because the oscillating heat flux does not represent a heat source and sink with zero average value. The "slow component" of the temperature increase must be removed and the measured data can be transformed into the form depicted in the middle of Figure 2, that is oscillations around zero average value. This transformation can be accomplished by many algorithms. The simplest one is subtracting a function describing the "slow component" (approximated by a piece-wise linear function, for example) so that the resulting average value is zero. Freund [9] mentioned that removing the exponential part of the time dependency should have no significant impact on the results.

On the basis of the transformed measured data, see Figure 2, it is then possible to find the phase shift $\varphi$. We used two methods in our case (their results are compared to detect possible discrepancies). The slower method uses a classic non-linear regression to find parameters of a model function describing the transformed experimental data. Equation (11) represents a suitable model function for approximating $\Delta T$. Then, parameters $A$ and $\varphi$ can be determined with the least-squares method based on the minimizing function

$$
\sum_{k}\left(\Delta T\left(t_{k}\right)-\Delta T_{k}\right)^{2}
$$

where $k$ is the index representing the sum over experimental data $\Delta T_{k}$ at times $t_{k}$ (see Figure 2). In practical implementation of this algorithm, we used the function nlinfit in system MATLAB ${ }^{\circledR}$.

The second method for evaluating the phase shift is based on the discrete Fourier transformation (DFT) 21] which seems to be very suitable with respect to the periodic behaviour of the signal. Coefficients $x_{n}$ of the Fourier series describing original signal $f$ can be determined as

$$
x_{n}=\frac{1}{N} \sum_{k=\{N\}} f(k) \mathrm{e}^{-2 \pi i k n / N}
$$

It is sufficient to analyse only the first harmonic component, in our case, this means that we can evaluate only the first coefficient in $(16)$ and express the value of the phase shift as

$$
\tan \varphi=\frac{\operatorname{Im}\left(x_{1}\right)}{\operatorname{Re}\left(x_{1}\right)}
$$

The DFT requires $N^{2}$ of operations for the transformation of the whole spectrum where $N$ is the number
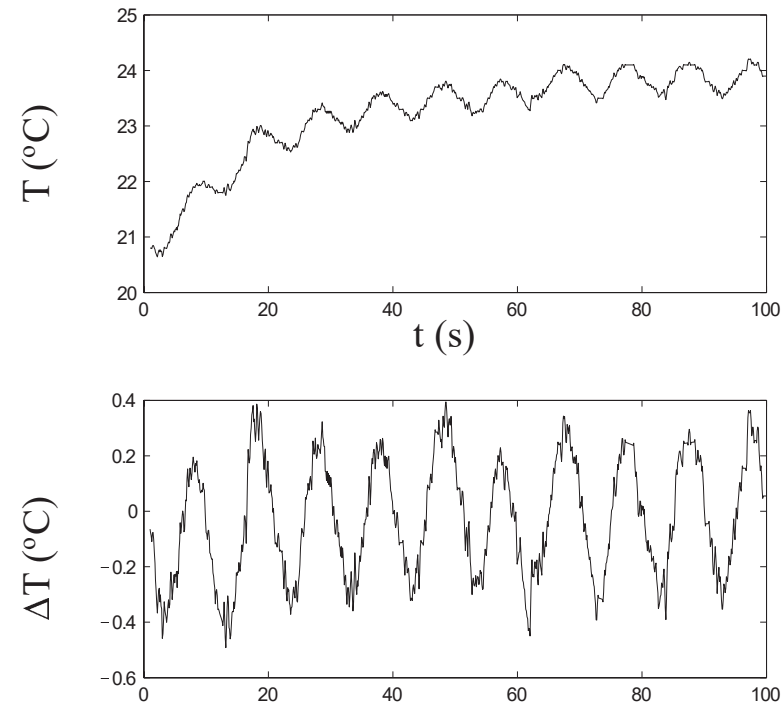

$\mathrm{t}(\mathrm{s})$

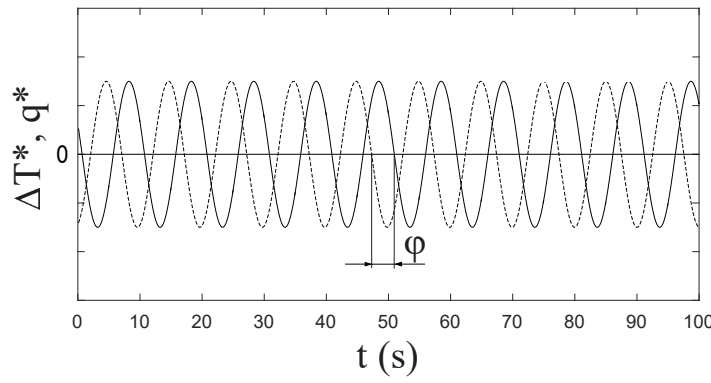

FiguRE 2. Illustration of processing the temperature time responses at the heat transfer surface measured by IR camera. (top) Original measured temperature response. (middle) Transformed temperature response oscillating around zero value, that is with removed accumulation (exponential) component. (bottom) Comparison of normalized values of the generated heat flux $q^{*}$ with first harmonics of the preprocessed temperature response $\Delta T^{*}$ in order to find out the phase shift $\varphi$.

of discrete points, therefore, it is substantially faster than the non-linear regression mentioned above.

\section{Applichtion of the Method}

The temperature oscillation method generates the sine-modulated heat flux and monitors the temperature fields in precise time intervals. To satisfy these requirements, we used the two-channel function generator BK Precision 4052. The first channel generates the sine wave in a voltage range of $3-10 \mathrm{~V}$. This signal is connected with $1.6 \mathrm{~kW}$ power supply and halogen lamps. We used $500 \mathrm{~W}$ linear halogen lamps because of their bad efficiency, therefore, most of the electric power is transformed to the heat flux. The second channel of the BK 4052 triggers the thermoIMAGER TIM 160 IR camera with a spatial resolution of $160 \times 120$ pixels. To get better results and constant emissivity $\varepsilon$, the 


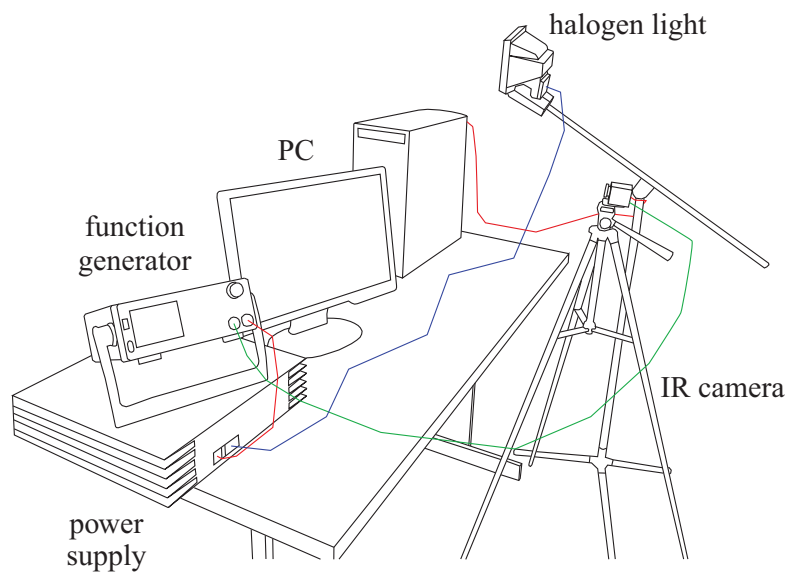

Figure 3. Wiring schematic and experimental equipment for the temperature oscillation method.

\begin{tabular}{lcc}
\hline & Phase shift $\left(^{\circ}\right)$ & $(\mathrm{ms})$ \\
\hline zero-heat method & 8.271 & 229 \\
\hline step-voltage method & 8.377 & 232 \\
\hline
\end{tabular}

TABlE 2. Time-frame synchronization results, the phase-shift results are for sine wave with period $10 \mathrm{~s}$ (frequency $0.1 \mathrm{~Hz}$ ).

target surfaces were painted by black matte spray colour with emissivity $\varepsilon=0.96$. The experimental equipment and wiring schematics are depicted in Figure 3

The phase-shift between the heat flux and wall temperature response must be measured precisely. Therefore, it is important to synchronize the heat flux and the IR camera trigger signal. The dynamic characteristic of the whole system, i.e. the voltage supply halogen lamps, has to be taken into account, otherwise, the experimental results would be affected by a systematic error. We used two methods to determine the dynamic characteristic. The first one measures the temperature response at one side of the heat transfer surface (wall), which is insulated on the other side (zero-heat method). The phase shift is then determined from the shift between the signal controlling the heat flux and the temperature response signal. The second method measures the transition characteristic of the voltage supply - the halogen lamp system on the basis of a step change of the voltage supply control input and the corresponding heat flux measurement (step-voltage method). Assuming the system is of the first order, the phase shift can be determined as the time constant of the measured response. The dynamic characteristic of the system, i.e., time constant, depends only on the properties of the system and not on the period of the oscillating signal. Nevertheless, several periods were tested $(2,5,10$ and $20 \mathrm{~s}$, with corresponding frequencies $0.5,0.2,0.1$, and $0.05 \mathrm{~Hz}$ ) and same results were obtained. The comparison of both methods is in Table 2

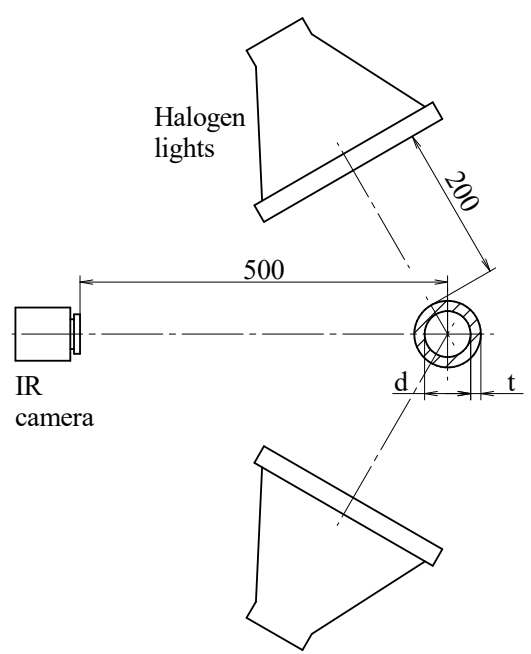

Figure 4. Pipe-flow experiment with copper pipe $26 \times 1 \mathrm{~mm}$.

\subsection{VAlidation OF the METHOD: PIPE FLOW}

The TOIRT experimental method was validated on two cases: a flow of water in a pipe, and a jet of water impinging a plate perpendicularly.

The mean temperature of the liquid (water) was maintained within the range of $16 \pm 1.5^{\circ} \mathrm{C}$ during the pipe-flow experiment. Corresponding liquid properties at this temperature are: density $999 \mathrm{~kg} \mathrm{~m}^{-3}$, thermal conductivity $0.598 \mathrm{~W} \mathrm{~m}^{-1} \mathrm{~K}^{-1}$, dynamic viscosity $1.1 \mathrm{mPas}$, and Prandtl number 7.36. Temperature of the flowing liquid was measured at the inlet and outlet of the measuring section. The maximum temperature increase of the outer pipe surface was $5{ }^{\circ} \mathrm{C}$ during the experiments. Neglecting the thermal resistance of the wall and the heat accumulation, we could assume the same liquid temperature at the inner pipe surface. The dynamic viscosity for this temperature is $0.98 \mathrm{mPa}$. Taking into account the temperature dependency of the viscosity as described by Sieder-Tate's correction, its influence would be $(0.98 / 1.1)^{0.14}=0.98$, that is $2 \%$. This influence was neglected. Water was pumped from a water tank by a centrifugal pump and it flowed through a copper pipe (density $8941 \mathrm{~kg} \mathrm{~m}^{-3}$, thermal conductivity $392 \mathrm{~W} \mathrm{~m}^{-1} \mathrm{~K}^{-1}$, thermal diffusivity $\left.1.136 \times 10^{-4} \mathrm{~m}^{2} \mathrm{~s}^{-1}\right)$ with an inner diameter of $d=24 \mathrm{~mm}$. The measurement section (100 mm long, approx. $4 d$ ) started at the distance approximately $L=80 d$ from the inlet, therefore, we assumed a fully developed velocity profile there. The volumetric flow rate was measured by the induction flow meter (Krohne IFC010D) and it was used in the calculation of the mean velocity $u$ in the pipe and consequently the Reynolds number according to (5). The experimental setup is in Figure 4 According to the distance of the IR camera from the surface, the size of the measured point was $0.75 \mathrm{~mm} / \mathrm{px}$.

Heat transfer coefficients were measured in the range of Reynolds number from $10^{4}$ to $5 \times 10^{4}$ and 


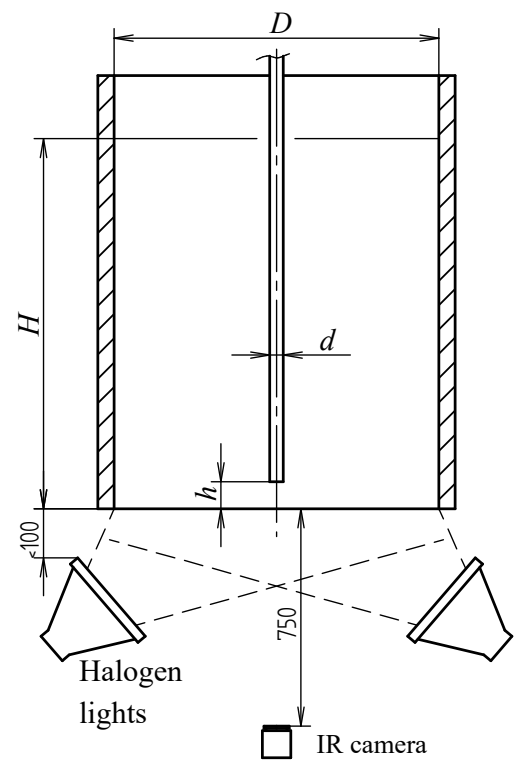

FIGURE 5. Impinging jet experiment.

with various parameters: the period of the sine wave 10 or $20 \mathrm{~s}$, scan frequency of the IR camera 10 or $20 \mathrm{~Hz}$ and the power modulation between 30 and $100 \%$. The heat transfer coefficients were evaluated at the inner side of the pipe wall and the results were described as the Nusselt number dependency on the Reynolds number

$$
\mathrm{Nu}=C \operatorname{Re}^{m} \operatorname{Pr}^{0.4}
$$

where $\operatorname{Pr}^{0.4}$ is the Prandtl number with a commonly used exponent for heating. Our evaluated dependency (Re from $10^{4}$ to $5 \times 10^{4}$ ) was

$$
\mathrm{Nu}=0.029 \operatorname{Re}^{0.8} \operatorname{Pr}^{0.4}
$$

which is very close to the well-known Dittus-Boelter correlation

$$
\mathrm{Nu}=0.023 \operatorname{Re}^{0.8} \operatorname{Pr}^{0.4},
$$

valid for $\operatorname{Re}>10^{4}$ and Pr from 0.6 to 160 .

\subsection{VALIDATION OF THE METHOD: IMPINGING JET FLOW}

Heat transfer in an impinging jet was investigated at a plane stainless steel plate (density $7800 \mathrm{~kg} \mathrm{~m}^{-3}$, thermal conductivity $14.6 \mathrm{~W} \mathrm{~m}^{-1} \mathrm{~K}^{-1}$ and thermal diffusivity $3.736 \times 10^{-6} \mathrm{~m}^{2} \mathrm{~s}^{-1}$ ) of a diameter of $392 \mathrm{~mm}$. The stainless plate formed a flat bottom of a cylindrical unbaffled vessel and it was impinged by a liquid stream coming from the pipe of an inner diameter of $22 \mathrm{~mm}$, see Figure 5 The jet outlet nozzle was located at $h / d=1$ above the vessel bottom.

The centrifugal pump controlled by an electric frequency inverter formed a closed loop with the water in the vessel, hence the water level was constant during the experiment. The volumetric flow was measured by the induction flow meter (Krohne OptiFlux 5300 ) and it was used in calculating the mean velocity

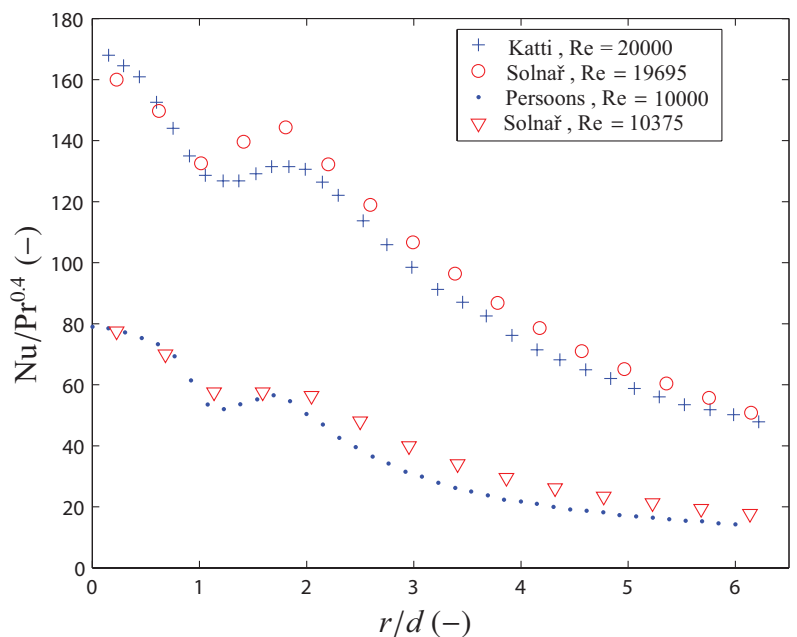

FiguRE 6. Comparison of measured experimental data for the impinging jet validation case, $h / d=1$, Solnař 22 with literature data by Persoons et al. [12, and Katti and Prabhu [4].

in the pipe and Reynolds number according to (5). The mean temperature of the liquid was maintained within a range of $20.5 \pm 1.5^{\circ} \mathrm{C}$ during the experiment. Corresponding liquid properties are: density 998.1 $\mathrm{kg} \mathrm{m}^{-3}$, thermal conductivity $0.605 \mathrm{~W} \mathrm{~m}^{-1} \mathrm{~K}^{-1}$, dynamic viscosity $0.99 \mathrm{mPa}$, and Prandtl number 6.92 . According to the distance of the IR camera from the bottom (see Figure 5), the size of the measured point was $3.3 \mathrm{~mm} / \mathrm{px}$. Figure 6 compares the experimental results [22] with literature data [4, 12] for two different Reynolds numbers.

\section{EXPERIMENTAL SETUP}

Schematic drawings of the agitated vessel (stainless steel, inner diameter $D=300 \mathrm{~mm}$ ) with two types of impellers (axial and radial impellers) and four baffles (angle $90^{\circ}$ ) are depicted in Figure 7 .

The axial down-pumping impeller (6PBT45) with six pitched blades (pitch angle $=45^{\circ}$ ) and diameter $d=100 \mathrm{~mm}$ (ratio $D / d=3$ ) was used. The radial impeller was a Rushton turbine with the same diameter as the axial-flow impeller. The thickness of the vessel wall was $1.03 \mathrm{~mm}$ and it was coated by a black matte colour at the outer side of the vessel in the area between baffles (the measurement area). Thermophysical properties of the vessel wall were: thermal conductivity $14.6 \mathrm{~W} \mathrm{~m}^{-1} \mathrm{~K}^{-1}$, density $7800 \mathrm{~kg} \mathrm{~m}^{-3}$ and specific heat capacity $501 \mathrm{~J} \mathrm{~kg}^{-1} \mathrm{~K}^{-1}$. The water level in the vessel was $H=D$. The height of impellers $h$ above the bottom and water level $H$ were adjusted with an accuracy of $1 \mathrm{~mm}$. The IR camera monitored the temperature field along the height of the vessel wall with a spatial resolution of about $2.5 \mathrm{~mm} / \mathrm{px}$. The sensitivity of the IR camera was $0.08 \mathrm{~K}$. The temperature of the liquid in the vessel was measured by a Pt1000 temperature sensor. It was within a range of $22.0 \pm 0.7^{\circ} \mathrm{C}$, and corresponding properties of 

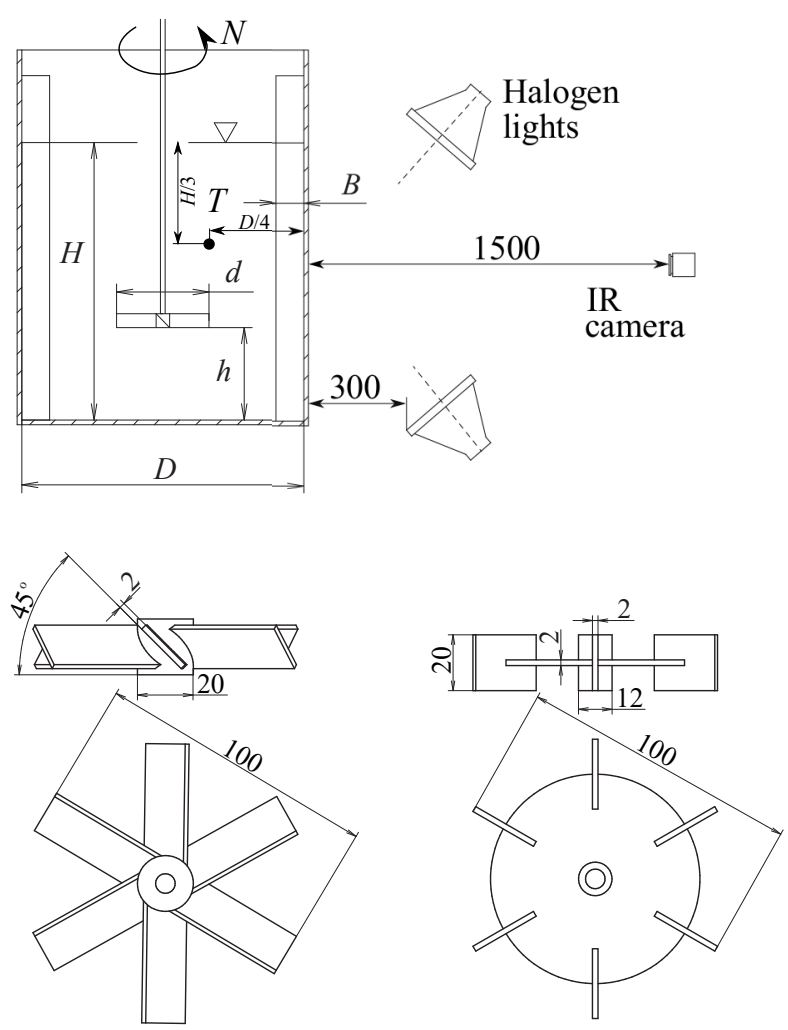

FigURE 7. Schematic drawings of our experimental vessel with four baffles and an impeller. (left) axialflow impeller 6PBT45, (right) Rushton turbine.

water are: density $997.8 \mathrm{~kg} \mathrm{~m}^{-3}$, thermal conductivity $0.605 \mathrm{~W} \mathrm{~m}^{-1} \mathrm{~K}^{-1}$, dynamic viscosity $0.99 \mathrm{mPa} \mathrm{s}$, and Prandtl number 6.92 .

Both impellers were situated at $h / d=1$ above the vessel bottom. Radial baffles of a width $B=0.1 D$ were used in both cases. The Reynolds number in a mixing system is defined by (6) with the impeller diameter as the characteristic dimension $d$. The Reynolds number, in the case of $6 \mathrm{PBT} 45$, was within the range $9 \times 10^{3}-9 \times 10^{4}$, and in the case of Rushton turbine, the range was $9 \times 10^{3}-6 \times 10^{4}$.

The following parameters were used in each experiment: the period of the sine wave 10 or $20 \mathrm{~s}$, the number of periods 5 or 10 , and the sampling frequency of the IR camera was always set to $10 \mathrm{~Hz}$.

\section{EXPERIMENTAL RESULTS}

Local values of the Nusselt numbers can be calculated according to (2), and it is possible to express the mean Nusselt number dependency by a commonly used correlation (18).

Two forms of experimental data are presented in this paper. The first one describes graphical dependencies of the local Nusselt number on dimensionless height $z / H$ for various Reynolds numbers (Re from $10^{4}$ to $\left.5 \times 10^{4}\right)$. The second form describes the mean Nusselt number along the wall as a function of the Reynolds number.

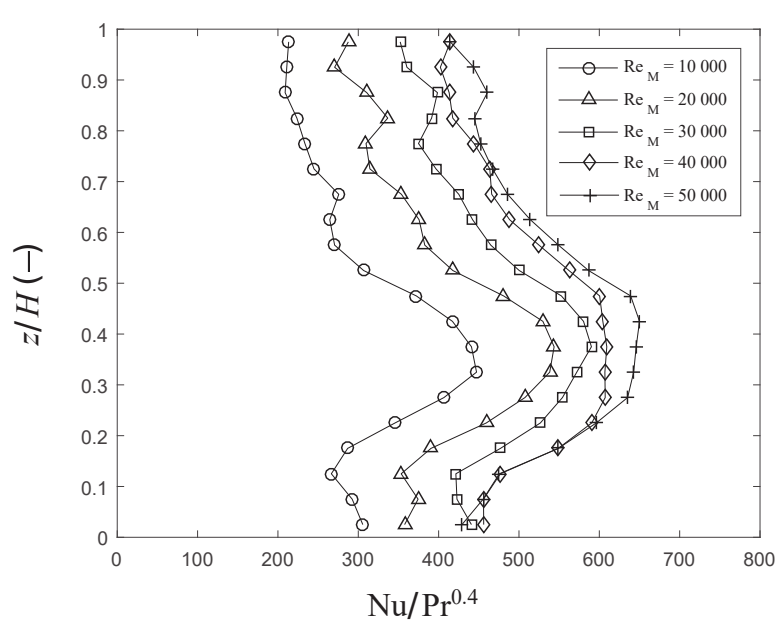

Figure 8. Nusselt number profile on the wall of the vessel with baffles, Rushton turbine, Re from $10^{4}$ to $5 \times 10^{4}$.

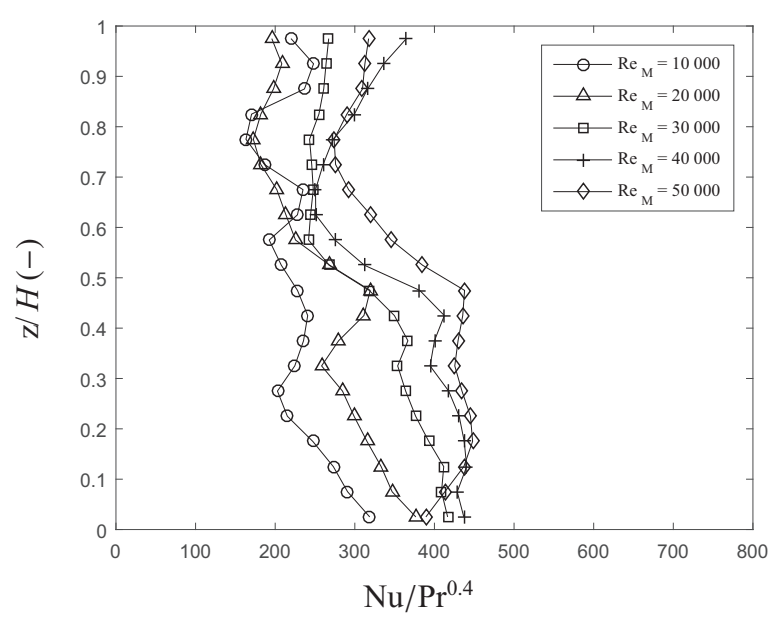

Figure 9. Nusselt number profile on the wall of the vessel with baffles, 6PBT45 down-pumping axial-flow impeller, Re from $10^{4}$ to $5 \times 10^{4}$.

The Nusselt number profiles for various Reynolds numbers and the Rushton turbine are in Figure 8 There is a significant peak of the Nusselt number at a dimensionless height $z / H=0.33$, which corresponds to the impeller location. Above $z / H>0.4$, the measured data show an exponential dependency.

Figure 9 illustrates the Nusselt number profiles for various Reynolds numbers and the 6PBT45 axial-flow impeller. The Nusselt numbers are slightly larger in the lower part of the vessel, from $z / H=0$ to $z / H=$ 0.5 , but there is no visible peak in the Nusselt number dependency as in the case of the Rushton turbine. The axial-flow impeller was located at $z / H=0.33$. The local values of the Nusselt number in Figures 8 and 9 were evaluated as average values over the width of the monitored surface at a specific dimensionless distance from the bottom $z / H$.

Mean values of the Nusselt number along the vessel wall and their dependencies on the Reynolds number 


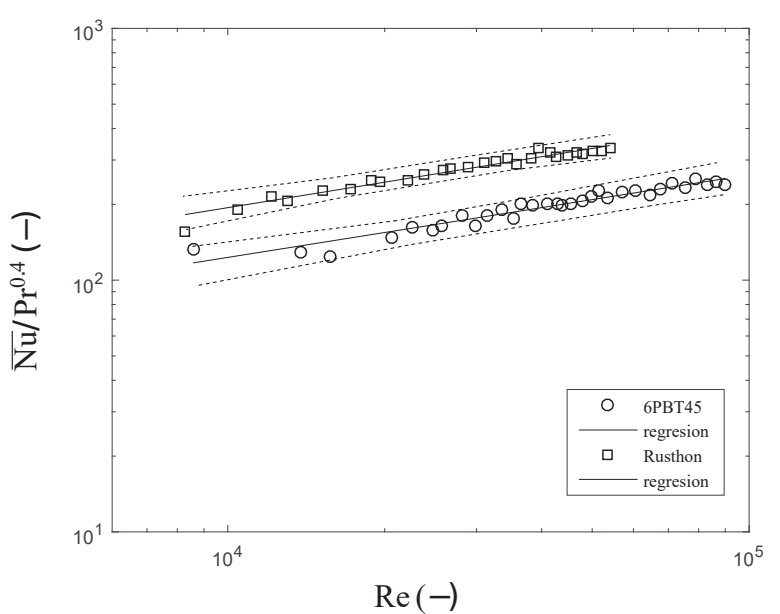

Figure 10. Mean values of the Nusselt numbers along the wall of the agitated vessel and the nonlinear regression lines based on the model function 18 . Dotted lines represent $95 \%$ confidence bands of the fitted functions. The width of these bands is no more than $\pm 15 \%$.
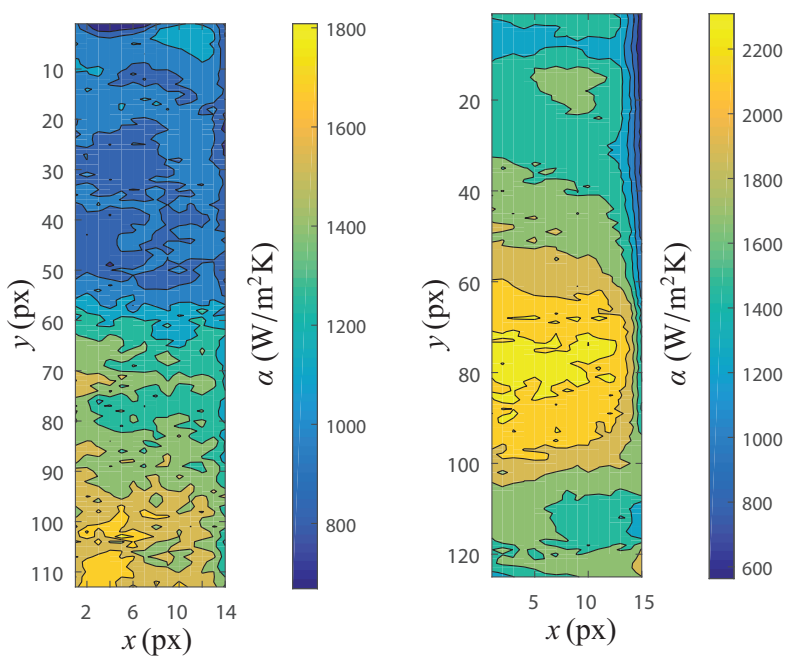

FIGURE 11. Comparison of the heat transfer intensity (coefficients) at the wall of the agitated vessel: 6PBT45 axial-flow impeller (left), Rushton turbine (right). Re $=3 \times 10^{4}$ for both cases.

are displayed in Figure 10. The dotted lines represent $95 \%$ confidence bands, which are no more than $\pm 15 \%$ wide in our case. Evaluated parameters of the correlation (18) are summarized in Table 3 for both cases, the Rushton turbine and the 6PBT45 axial-flow impeller. Contours of the heat transfer coefficients at the wall are depicted in Figure 11. The part of the tank wall monitored by the IR camera is represented by $120 \times 15$ pixels here, that is $300 \times 37.5 \mathrm{~mm}$ according to the camera resolution $2.5 \mathrm{~mm} / \mathrm{px}$. This means that the wall temperature was monitored along the whole height of the liquid in the vessel $(\mathrm{H}=300 \mathrm{~mm})$.

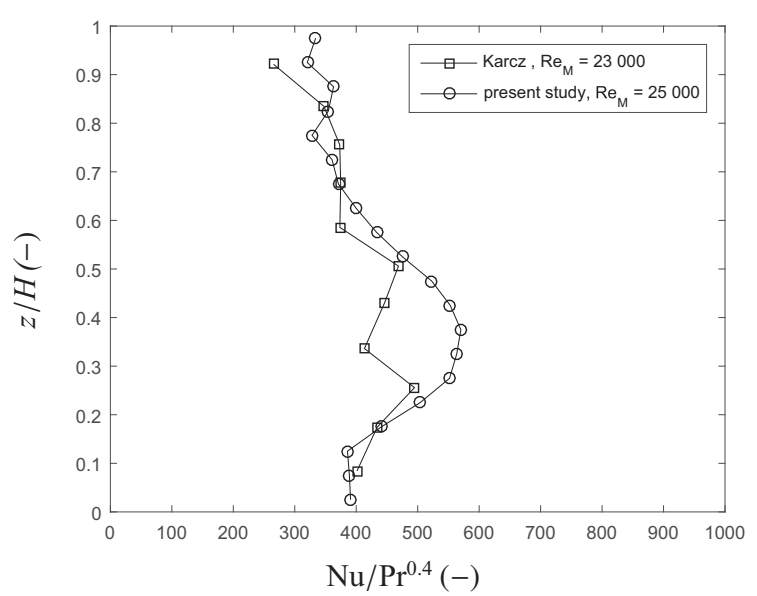

Figure 12. Comparison of the experimental results for the Rushton turbine with Karcz and Cudak 18

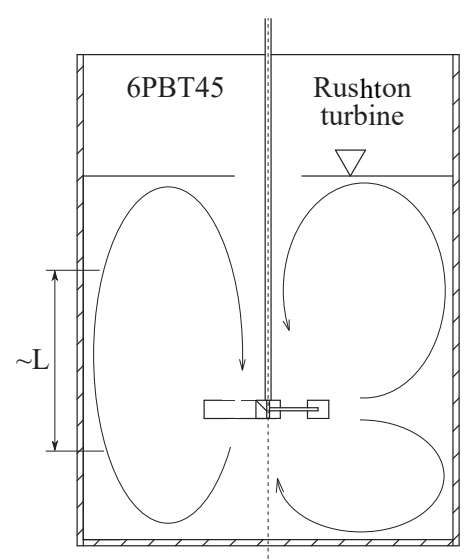

FIGURE 13. Illustration of flow patterns and regions, where similarities between the flow along a flat plate and the flow along the wall of the agitated vessel with axial-flow (left) and radial-flow (right) impeller can be identified.

\section{Discussion}

Figure 12 shows a good agreement of our experimental results for the Rushton turbine with $\mathrm{Karcz}$ and $\mathrm{Cu}-$ dak [18] measured by the EDD experimental method. A bigger difference (approx. 50\%) is visible within the range $z / H=0.25-0.5$ where we have a clearly smoother distribution of experimental data.

Vlček et al. 223. studied velocity fields in a vessel agitated by the 6 PBT45 impeller using LDA experiments and LES-based simulations in ANSYS CFD software.

\begin{tabular}{lll}
\hline & $C$ & $m$ \\
\hline Rushton turbine & $8.75 \pm 33 \%$ & $0.336 \pm 9.5 \%$ \\
\hline 6PBT45 & $5.98 \pm 34 \%$ & $0.328 \pm 9.6 \%$ \\
\hline
\end{tabular}

TABle 3. Evaluated parameters of 18 for mean values of the Nusselt number $\overline{\mathrm{Nu}}$. 
They reported that dimensionless axial velocity near the wall of the vessel

$$
u_{\mathrm{ax}}^{*}=\frac{u_{\mathrm{ax}}}{\pi d N}
$$

equals approximately to 0.3 in the middle region of the vessel wall. Assuming a characteristic length of this region according to Vlček et al. [23] as 2/3 of water level $H$, it is possible to calculate the mean axial velocity near the vessel wall and the corresponding Reynolds number. In the case of rotation speed $N=$ $300 \mathrm{~min}^{-1}$, the mean axial velocity along the wall is $u_{\mathrm{ax}}=0.43 \mathrm{~m} \mathrm{~s}^{-1}$ and the corresponding Reynolds number

$$
\operatorname{Re}_{\mathrm{L}}=\frac{u_{\mathrm{ax}} L \rho}{\mu}
$$

is 94000 . With the well-known correlation describing the flow along a flat plate ([24], valid for $\operatorname{Re}<10^{5}$ and $\operatorname{Pr}>0.6$ )

$$
\mathrm{Nu}=0.664 \operatorname{Re}_{\mathrm{L}}^{0.5} \operatorname{Pr}^{0.33}
$$

it is possible to calculate the Nusselt number as 395 . Using (6) and rotation speed $N=300 \mathrm{~min}^{-1}$, the Reynolds number in the agitated vessel $R_{M}$ is 50000 . Substituting to correlation (18) for the 6PBT45 axial impeller and a same Prandtl number, we can evaluate the Nusselt number $\mathrm{Nu}=404$, which is quite close to the value based on the case of the flow along a plate (error $2.3 \%$ ).

In the case of the vessel agitated by the $6 \mathrm{PBT} 45$ impeller, it is possible to find regions with some similarities between the heat transfer at the vessel wall and the heat transfer in a flow along a flat plate. Such regions with similar results cannot be identified in the case of the Rushton turbine (radial-flow impeller).

The evaluated experimental data do not show similarities with the flow along the flat plate for the entire height of the vessel wall. In general, such similarities can be found only in regions where the flow is aligned with the vessel wall. Such regions are larger in configurations with an impeller placed in a draft tube [25], or in cases with axial-flow impellers and larger $H / D$ ratio.

\section{Conclusion}

The temperature oscillation infra-red thermography method was used for measuring local heat transfer coefficients at the wall of an agitated vessel with four baffles. The Rushton turbine and a 6PBT45 axial-flow impeller located at dimensionless distance $z / H=0.33$ from the vessel bottom were used in the experiments.

We have validated the TOIRT method on the pipe flow and impinging jet experiments. The experimental results of the heat transfer in the agitated vessel are presented as graphical dependencies of the Nusselt number with respect to a dimensionless coordinate $z / H$. In the case of the Rushton turbine, a significant peak of the Nusselt number at the vessel wall can be observed around $z / H=0.33$ (the impeller location).
No such peak can be identified in the case of the axial-flow impeller 6PBT45.

Parameters of the commonly used correlation for the mean Nusselt number were evaluated in both cases, the Rushton turbine and 6PBT45 axial-flow impeller. Similarities between the heat transfer at the wall of the vessel agitated by the 6PBT45 impeller and the flow along a flat plate can be identified in some regions of the wall, but they cannot be recognized for the entire height of the vessel wall or the Rushton turbine impeller.

The disadvantages of the TOIRT method consist in the necessity of an accurate measuring of the wall temperature response. The temperature variations are relatively small, therefore, relatively expensive IR cameras with good sensitivity are required, otherwise, the key parameter of this method, the phase shift, is determined inaccurately and the resulting value of the heat transfer coefficient is inaccurate as well. Another problem lies in light reflections from the surface irradiated by the halogen lamps, which could easily distort the image scanned by the IR camera. Nevertheless, we think that the advantages of the TOIRT method prevails and they can be briefly summarized as (1) contactless, (2) relatively fast for a heat transfer measurement, (3) with an option to easily change the spatial resolution.

\section{LIST OF SYMBOLS}

$a$ thermal diffusivity (of liquid) $\left[\mathrm{m}^{2} \mathrm{~s}^{-1}\right]$

$a_{\mathrm{w}}$ thermal diffusivity of wall $\left[\mathrm{m}^{2} \mathrm{~s}^{-1}\right]$

$A$ amplitude [K]

$B$ baffle width $[\mathrm{m}]$

C geometric constant [-]

$c_{0,1,2,3}$ dimensionless parameters $[-]$

$c_{p} \quad$ specific heat capacity $\left[\mathrm{J} \mathrm{kg}^{-1} \mathrm{~K}^{-1}\right]$

$d$ characteristic length, impeller or pipe diameter [m]

$D$ vessel diameter $[\mathrm{m}]$

$h$ height of impeller of tube above bottom [m]

$H$ height of water level [m]

$L_{\text {char }}$ characteristic length $[\mathrm{m}]$

$m, n$ exponents [-]

$N$ rotation speed $\left[\mathrm{s}^{-1}\right]$

$N$ number of experimental points [-]

$\mathrm{Nu}$ Nusselt number [-]

$\overline{\mathrm{Nu}}$ mean Nusselt number, see $(3)[-]$

Pr Prandtl number [-]

$q$ heat flux $\left[\mathrm{W} \mathrm{m}^{-2}\right]$

$\hat{q}$ amplitude of heat flux [ $\left.\mathrm{W} \mathrm{m}^{-2}\right]$

$\dot{Q}$ heat flow rate $[\mathrm{W}]$

$r$ dimensionless parameter [-]

Re Reynolds number [-]

$\operatorname{Re}_{\mathrm{M}}$ mixing Reynolds number [-]

$\mathrm{Re}_{\mathrm{L}}$ Reynolds number for flat plate [-]

$S$ surface $\left[\mathrm{m}^{2}\right]$

$t$ time [s]

$T$ temperature $\left[{ }^{\circ} \mathrm{C}, \mathrm{K}\right]$ 
$\Delta T$ temperature difference $\left[{ }^{\circ} \mathrm{C}, \mathrm{K}\right]$

$u$ mean velocity $\left[\mathrm{m} \mathrm{s}^{-1}\right]$

$u_{\text {ax }}$ axial part of velocity $\left[\mathrm{m} \mathrm{s}^{-1}\right]$

$u_{\mathrm{ax}}^{*}$ dimensionless velocity [-]

$x_{1}, x_{n}$ coefficients in Fourier's series

$x, y, z$ coordinate $[\mathrm{m}]$

$\alpha$ heat transfer coefficient $\left[\mathrm{W} \mathrm{m}^{-2} \mathrm{~K}^{-1}\right]$

$\alpha_{0}$ heat transfer coefficient at the coordinate $z=0$ $\left[\mathrm{W} \mathrm{m}^{-2} \mathrm{~K}^{-1}\right.$ ]

$\alpha_{\delta}$ heat transfer coefficient at the coordinate $z=\delta$ $\left[\mathrm{W} \mathrm{m}^{-2} \mathrm{~K}^{-1}\right]$

$\delta \quad$ wall thickness $[\mathrm{m}]$

$\varepsilon$ emissivity $[-]$

$\lambda$ thermal conductivity of liquid $\left[\mathrm{W} \mathrm{m}^{-1} \mathrm{~K}^{-1}\right]$

$\lambda_{\mathrm{w}}$ thermal conductivity of wall $\left[\mathrm{W} \mathrm{m}^{-1} \mathrm{~K}^{-1}\right]$

$\mu$ dynamic viscosity [Pas]

$\nu \quad$ kinematic viscosity $\left[\mathrm{m}^{2} \mathrm{~s}^{-1}\right]$

$\rho$ density $\left[\mathrm{kg} \mathrm{m}^{-3}\right]$

$\varphi$ phase-shift $\left[^{\circ}, \mathrm{rad}\right]$

$\psi_{0}, \xi$ dimensionless parameters [-]

$\omega$ angular frequency $\left[\mathrm{s}^{-1}\right]$

ABbreviations

6BD six-blade disc impeller (Rushton turbine)

6PBT45 six-blade impeller with a pitched angle of $45^{\circ}$

CFD Computational Fluid Dynamics

DFT Discrete Fourier Transform

EDD Electro-Diffusion method

IR Infra Red

LES Large Eddy Simulation

LDA Laser Doppler Anemometry

TLC Thermochromic Liquid Crystals

TOIRT Temperature Oscillation Infra-Red Thermography

px pixel

\section{ACKNOWLEDGEMENTS}

This work is supported by a research project of the Grant Agency of Czech Republic No. 14-18955S.

\section{REFERENCES}

[1] M. Dostál, K. Petera, F. Rieger. Measurement of heat transfer coefficients in an agitated vessel with tube baffles. Acta Polytechnica 50:46-57, 2010.

[2] M. Dostál, M. Věříšová, K. Petera, et al. Analysis of heat transfer in a vessel with helical pipe coil and multistage impeller. Canadian Journal of Chemical Engineering 92(12):2115-2121, 2014. DOI:10.1002/cjce.22033

[3] D. Lytle, B. W. Webb. Air jet impingement heat transfer at low nozzle-plate spacing. International Journal of Heat and Mass Transfer 37(12):1687-1697, 1994. DOI:10.1016/0017-9310(94)90059-0

[4] V. Katti, S. Prabhu. Experimental study and theoretical analysis of local heat transfer distributions between smooth flat surface and impinging air jet from a circular straight pipe nozzle. International Journal of Heat and Mass Transfer 51(17):4480-4495, 2008. DOI:10.1016/j.ijheatmasstransfer.2007.12.024
[5] H. Akse, W. J. Beek, F. C. A. A. van Berkel, J. de Graauw. The local heat transfer at the wall of a large vessel agitated by turbine impellers. Chemical Engineering Science 22:135 - 146, 1967. DOI:10.1016/0009-2509(67)80006-X

[6] M. F. Edwards, W. L. Wilkinson. Heat transfer in agitated vessels. Part I - Newtonian fluids. The Chemical Engineer 264:310 - 319, 1972.

[7] J. Karcz. Studies of heat transfer process in agitated vessels. Trends in Chemical Engineering 8:161 - 182, 2003 .

[8] M. Wandelt, W. Roetzel. Lockin thermography as a measurement technique in heat transfer. Quantitative Infrared Thermography 96 pp. 189-194, 1997.

[9] S. Freund. Local Heat Transfer Coefficients Measured with Temperature Oscillation IR Thermography. Ph.D. thesis, Universitat der Budeswehr Hamburg, 2008.

[10] S. Freund, S. Kabelac. Investigation of local heat transfer coefficients in plate heat exchanger with temperature oscillation IR thermography and CFD. International Journal of Heat and Mass Transfer 53:3764-3781, 2010 . DOI:10.1016/j.ijheatmasstransfer.2010.04.027.

[11] S. Freund, A. G. Pautsch, T. A. Shedd, S. Kabelac. Local heat transfer coefficients in spray cooling systems measured with temperature oscillation IR thermography. International Journal of Heat and Mass Transfer 50:1953-1962, 2007. DOI:10.1016/j.ijheatmasstransfer.2006.09.028

[12] T. Persoons, K. Balgazin, K. Brown, D. B. Murray. Scaling of convective heat transfer enhancement due to flow pulsation in an axisymmetric impinging jet. International Journal of Heat and Mass Transfer 135 2013. DOI:10.1115/1.4024620

[13] M. Draksler, B. Končar, L. Cizelj, B. Niceno. Large eddy simulation of multiple impinging jets in hexagonal configuration - flow dynamics and heat transfer characteristics. International Journal of Heat and Mass Transfer 109:16-27, 2017. DOI:10.1016/j.ijheatmasstransfer.2017.01.080

[14] M. V. Jensen, J. H. Walther. Numerical analysis of jet impingement heat transfer at high jet Reynolds number at large temperature difference. Heat Transfer Engineering 34(10):801-809, 2013. DOI:10.1080/01457632.2012.746153

[15] N. Zuckerman, N. Lior. Jet impingement heat transfer: physics, correlations, and numerical modelling. Advances in Heat Transfer 39:565-631, 2006. DOI:10.1016/S0065-2717(06)39006-5

[16] K. Wichterle. Heat transfer in agitated vessels. Chemical Engineering Science 49(9):1480-1483, 1994. DOI:10.1016/0009-2509(94)85075-5

[17] P. Mohan, A. N. Emery, T. Al-Hassan. Review heat transfer to Newtonian fluids in mechanically agitated vessels. Experimental Thermal and Fluid Science 5:861 883, 1992. DOI:10.1016/0894-1777(92)90130-W

[18] J. Karcz, M. Cudak. Studies of local heat transfer at vicinity of a wall region of an agitated vessel. In Proc. 34th International conference of SSCHE 2007, pp. 029-1 - 029-10. 2007. 
[19] R. Engeskaug, E. Thorbjørnsen, H. F. Svendsen. Wall heat transfer in stirred tank reactors. Industrial $\&$ Engineering Chemistry Research 44:4949 - 4958, 2005. DOI:10.1021/ie049178a

[20] J. Vejrazka, P. Marty. An alternative technique for the interpretation of temperature measurements using thermochromic liquid crystals. Heat Transfer Engineering 28(2):154-162, 2007. DOI:10.1080/01457630601023641

[21] D. Sundararajan. The Discrete Fourier Transform: Theory, Algorithms and Applications. World Scientific Publishing Co. Inc., 2001.

[22] S. Solnař, K. Petera, M. Dostál, T. Jirout. Heat transfer measurements with TOIRT method. EPJ Web of Conferences 143:02113, 2017. DOI:10.1051/epjconf/201714302113

[23] P. Vlček, B. Kysela, T. Jirout, I. Fořt. Large eddy simulation of a pitched blade impeller mixed vessel comparsion with LDA measurement. Chemical Engineering Research and Design 108:42-48, 2016. DOI:dx.doi.org/10.1016/j.cherd.2016.02.020

[24] P. Stephan, H. Martin, S. Kabelac, et al. (eds.). VDI Heat Atlas. Springer, 2010.

[25] K. Petera, M. Dostál, M. Věříšova, T. Jirout. Heat transfer at the bottom of a cylindrical vessel impinged by a swirling flow from an impeller in a draft tube. Chemical and Biochemical Engineering Quarterly 31:343 - 352, 2017. DOI:10.15255/CABEQ.2016.1057 